\title{
ELECTROCARDIOGRAPHIC STUDIES DURING ATTACKS OF ANGINA PECTORIS AND OF OTHER PAROXYSMAL PAIN
}

\author{
By MORTIMER L. SIEGEL AND HAROLD FEIL \\ (From the Medical Service and the Cardiac Clinic of Mt. Sinai Hospital, Cleveland)
}

(Received for publication July 13, 1931)

The mechanism of the pain in angina pectoris has been the subject of speculation and investigation since the original report of this clinical condition by Heberden (9). Among the many theories there are two which today receive most support: (1) Coronary origin-(a) myocardial ischemia due either to sclerosis of the coronary arteries and consequent loss of elasticity or to coronary artery spasm; (b) distension of the sclerosed coronary arteries with stimulation of the periarterial sympathetic nerve fibers; and (2) Aortic origin-due to distension of the diseased supra-sigmoid portion of the aorta with tension on the nerve endings in the adventitia (Wenckebach; Allbutt). Recent electrocardiographic observations made during transient attacks of angina have revealed inversion of the $\mathrm{T}$ wave or $\mathrm{S}-\mathrm{T}$ segment of the curve, usually in leads I and II. There is immediate return of the curve to normal after subsidence of the pain. These electrocardiographic studies have been reported by several observers: Clerc (3), Arrilaga (1), Bousfield (2), Feil and Siegel (4), Levy (5), Parkinson and Bedford (6) and Wood and Wolferth (7). The clinical observations have been substantiated by the experimental work of Wood and Wolferth (7) who produced "temporary and rapidly reversible electrocardiographic changes analogous to those seen in angina pectoris tracings." These changes were: greater inversion of previously negative $T$ waves in some experiments and the production of a high take-off in the S-T complex in others. These investigators obtained abnormalities in the $\mathrm{T}$ wave more readily in abnormal hearts. Clamping of the circumflex and posterior descending coronary arteries caused greater changes than obstruction of the ramus descendens or branches of the right coronary artery. Feil, Katz, Moore, and Scott (8) in a recent experimental 
study obtained similar curves from ligature of the ramus descendens of the left coronary artery. These changes were most pronounced after further ischemia of the heart muscle was produced by obstruction of the inferior vena cava. These clinical and experimental data are strong evidence that myocardial ischemia is responsible for the changes in the $\mathrm{T}$ wave and $\mathrm{S}-\mathrm{T}$ segment of the curves. Likewise, they indicate that the pain is probably due to or associated with myocardial ischemia.

In this report are given the electrocardiographic findings in eleven additional cases with transient anginal attacks. Clinically, these cases may be divided into four groups: (1) Patients with coronary sclerosis and who were not known to have had coronary artery thrombosis; (2) Patients who had in addition, an attack of coronary thrombosis previously; (3) Patients whose angina was associated with aortic regurgitation; and (4) Patients who had angina and who subsequently developed coronary artery occlusion.

The results of these observations during anginal attacks are summarized in Table I.

TABLE I

Electrocardiographic changes

\begin{tabular}{|c|c|c|c|c|c|}
\hline Case & Diagnosis $†$ & $\mathrm{~T}_{\mathrm{I}}$ & $\mathrm{T}_{I I}$ & $\mathrm{~T}_{\text {III }}$ & Depression of S-T Segment \\
\hline $\begin{array}{r}1 \\
2 \\
3 \\
4 \\
5 \\
6 \\
7 \\
8 \\
9 \\
10 \\
11\end{array}$ & $\begin{array}{l}\text { C.S. } \\
\text { C.S.; R.C.T. } \\
\text { C.S.; O.C.T. } \\
\text { C.S.; O.C.T. } \\
\text { C.S.; O.C.T. } \\
\text { C.S. } \\
\text { A.I. } \\
\text { C.S. } \\
\text { C.S.; O.C.T. } \\
\text { C.S. } \\
\text { C.S. }\end{array}$ & neg. & $\begin{array}{l}\text { neg. } \\
\text { neg. }\end{array}$ & $\begin{array}{l}\text { neg. } \\
\text { neg. }\end{array}$ & $\begin{array}{l}\text { Leads } 2 \text { and } 3 \\
\text { Leads } 2 \text { and } 3 \\
\text { Leads } 1 \text { and } 2 \\
\text { Lead } 1 \\
\text { Leads } 1 \text { and } 2\end{array}$ \\
\hline
\end{tabular}

$\dagger$ C.S.-Coronary sclerosis. R.C.T.-Recent coronary thrombosis. O. C.T.-Old coronary thrombosis. A.I.-Aortic insufficiency, rheumatic.

\section{CASE REPORTS}

Case 1. L. F., female, aged 56. Diagnosis: Coronary sclerosis with gradual obliterative arteritis and myocardial fibrosis. She had attacks of substernal pain with radiation to the left shoulder and down the left arm. These attacks had been recurring for two years, usually after emotional up- 
set and were not precipitated by exercise. The blood pressure was usually $150 / 90$ but during the attack rose to $170 / 100$. The heart rate usually 80 , rose to 120 and the cardiac mechanism remained normal. Physical examination revealed a heart normal in size and heart sounds that were feeble. The first heart sound at the apex was especially faint and gallop rhythm was present much of the time. During the latter part of the patient's illness there were attacks of pulmonary edema and the terminal illness was dominated by congestive failure. Postmortem examination revealed advanced arteriosclerosis of both coronary arteries with almost complete obliteration of the lumen of the ramus descendens. There was advanced sclerosis of the muscle of the anterior and lateral part of the left ventricle. An electrocardiogram taken on November 13, 1928 (Fig. 1, a) during an attack revealed normal mechanism, rate 136; the S-T segment in lead I rose after the completion of $R$ and $T$ was elevated $2 \mathrm{~mm}$. The $\mathrm{S}-\mathrm{T}$ segment in lead II was somewhat depressed and $\mathrm{T}$ was upright. Lead III shows depression of the $\mathrm{S}-\mathrm{T}$ portion of the curve. An electrocardiogram taken after the attack subsided (Fig. 1, b) showed T 1 to be almost isoelectric; S-T 2 was slightly depressed; T 2 and T 3 were both upright. The rate was 100 .

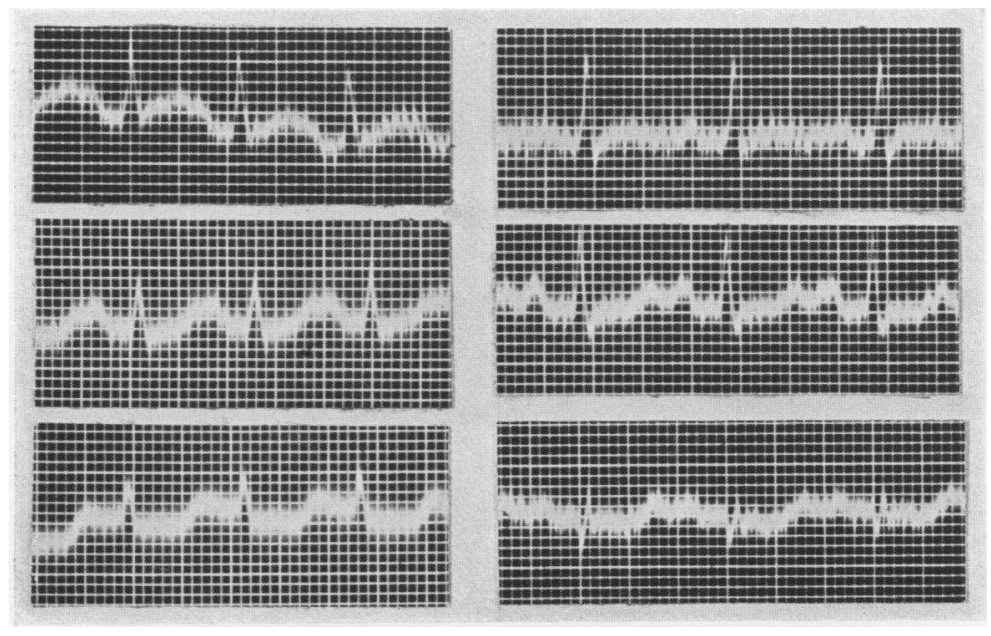

FIG. 1, a

FIG. 1, b

Case 2. C. H., male, aged 62. Diagnosis: Coronary sclerosis with angina pectoris, recent coronary thrombosis. For several months he had attacks of substernal pain on effort, relieved by nitrites. A severe attack of substernal pain occurred three weeks before the electrocardiographic study was made. This attack was probably due to coronary thrombosis. The patient had had elevation of the systolic and diastolic blood pressure for approxim- 


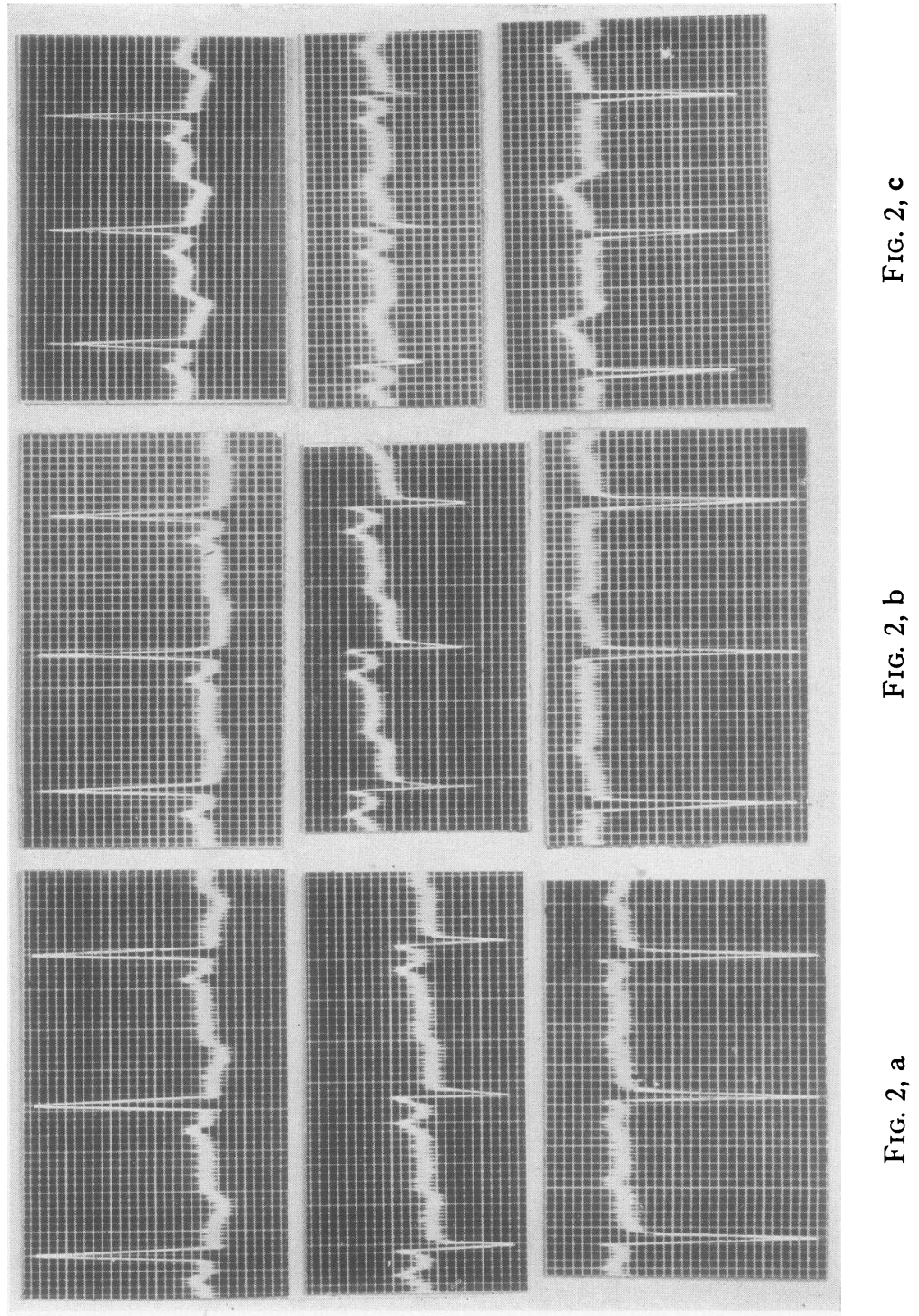


ately eighteen years (180/110). An electrocardiogram (Fig. 2, a) taken on December 29, 1929 revealed inversion of T 1; depression of S-T 2 and T 2 was upright; $\mathrm{T} 3$ was upright. Immediately after this record was taken the patient complained of severe pain (Fig. 2, b) which showed a greater depression of S-T 2. There was less depression of the S-T segment in lead III. The patient inhaled amyl nitrite and was relieved of pain. Figure 2, c, shows a striking change: T 1 is more deeply depressed; $\mathrm{S}-\mathrm{T} 2$ is isoelectric; $\mathrm{S}-\mathrm{T} 3$ is slightly elevated and T 3 is larger.

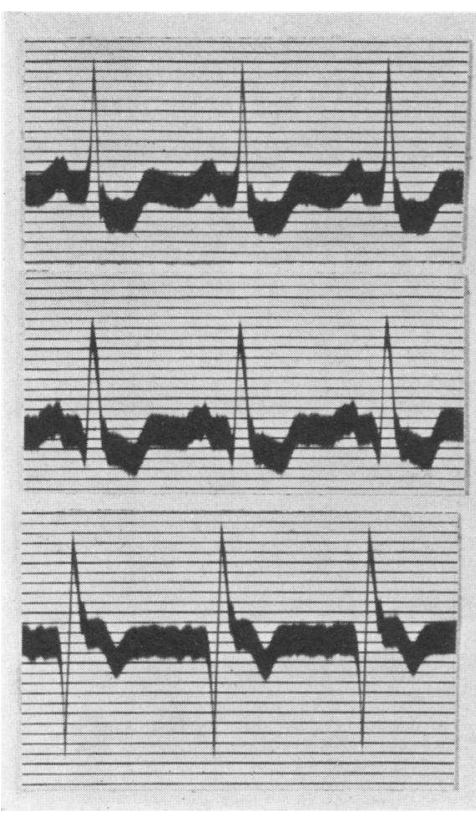

FIG. 3, a

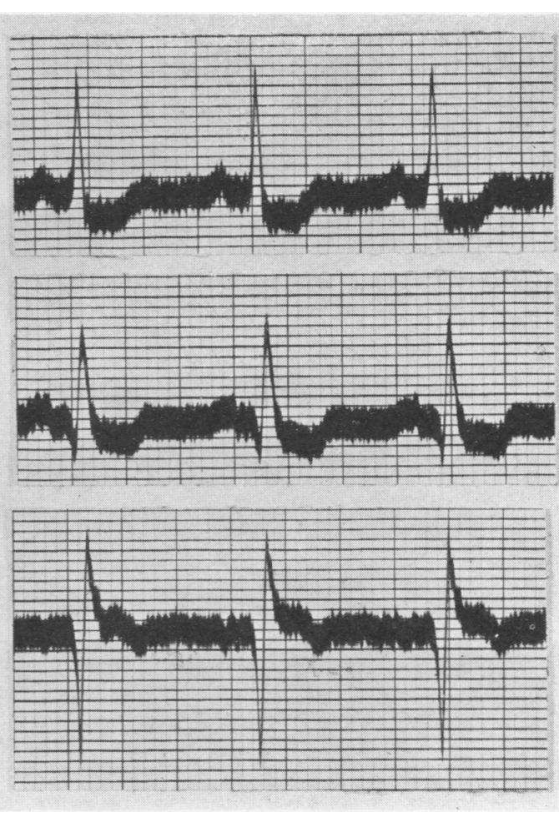

Fig. 3, b

Case 3. J. W., male, aged 61. Diagnosis: Coronary sclerosis with angina pectoris, old coronary thrombosis. Chief complaint: substernal pain on effort, with radiation to neck, left shoulder and arm. Symptoms dated from a sudden and severe attack of substernal pain August 1927 (1 year before observation). Generalized arteriosclerosis. Blood pressure 150/100. Moderate enlargement of left ventricle. An electrocardiogram taken on May 31, 1928 during an attack of angina (Fig. 3, a) revealed a depression of the S-T segment in leads I and II. A very deep $Q$ is seen in lead III and $\mathrm{S}-\mathrm{T} 3$ has a high take-off and is curved with its convexity upwards. A record taken a few minutes later after subsidence of the pain (Fig. 3, b) shows less depression of S-T in leads I and II. 
Case 4. H. M., male, aged 48. Diagnosis: Coronary sclerosis, angina pectoris, recent coronary thrombosis. Coronary thrombosis July 1929. Attacks of typical angina with effort and emotion. Moderate cardiac enlargement. Blood pressure 160/120. An electrocardiogram was taken one month after occlusion during an attack of angina. Figure 4, a, shows considerable depression of the $\mathrm{S}-\mathrm{T}$ segment in lead $\mathrm{I}$; slight inversion of $\mathrm{T} 2$ and a moderately high take-off of S-T 3 with inversion of T 3 . Immediately after subsidence of the pain the electrocardiogram (Fig. 4, b) shows less inversion of S-T 1; greater inversion of T 2 and an altered QRS complex in lead III.

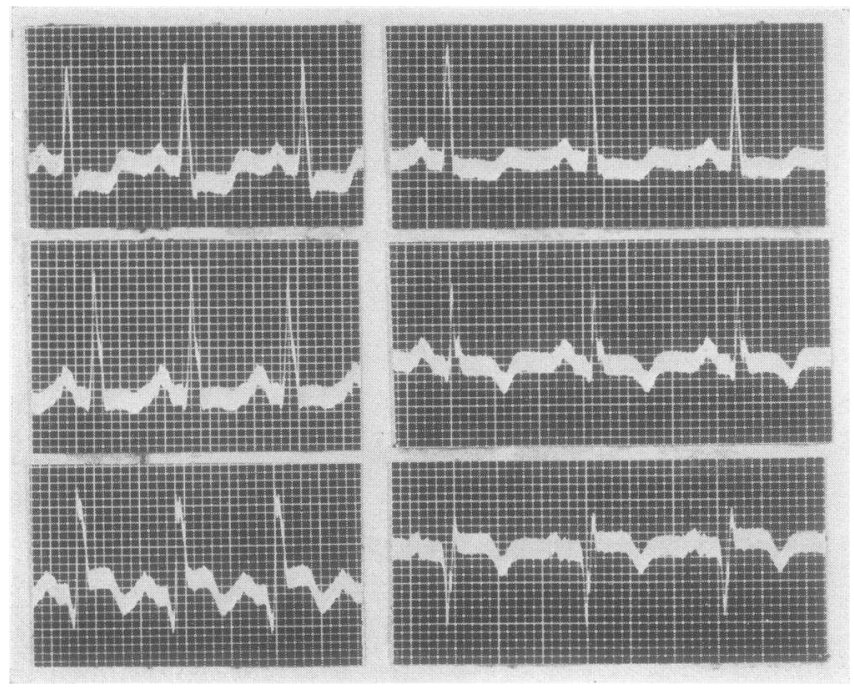
FIG 4 , a
FJG. 4, b

Case 5. M. F., male, aged 58. Diagnosis: Coronary sclerosis; angina pectoris; old coronary thrombosis. Had attack of coronary thrombosis April 28, 1927. Moderate cardiac enlargement to the left. Blood pressure 200/110. Moderate generalized arteriosclerosis. An electrocardiogram taken on August 30, 1930 (Fig. 5, a) during a severe anginal attack revealed a deeply depressed S-T segment in leads I and II and in lead III T is isoelectric. A record taken after relief by inhalation of amyl nitrite shows very slight depression of S-T in leads I and II and in lead III T becomes depressed.

Case 6. M. B., female, aged 53. Diagnosis: Coronary sclerosis; angina pectoris. Typical angina of effort in substernal region with radiation to the left shoulder and arm. Duration six years. Heart not enlarged. Blood pressure 180,100 . An electrocardiogram was taken on October 16, 1930 
during an attack of severe angina. Figure 6, a, shows the striking inversion of $\mathrm{T} 1$ and $\mathrm{T} 2$. A record taken immediately after relief by the inhalation of amyl nitrite shows a lessening of this depression of $T 1$ and 2 (Fig. 6, b).

Case 7. E. F., female, aged 24. Diagnosis: Free aortic insufficiency (rheumatic) with nocturnal attacks of angina pectoris. Chorea at the age of 13 (heart affected then) with recurrent attacks of rheumatic fever during succeeding years. For 7 or 8 years patient had had nocturnal attacks of pain in the substernal region, radiating to the left shoulder and down the

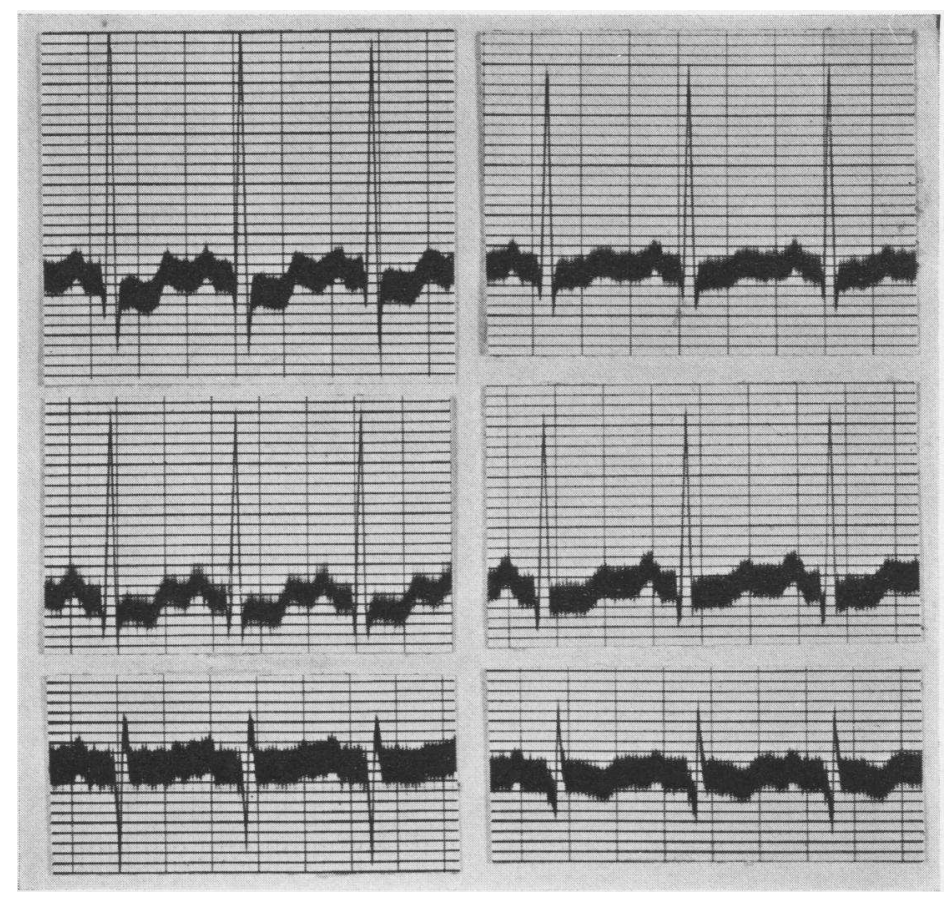

FIG. 5, a

FIG. 5, b

left arm. There have been no signs of congestive failure. The blood Wassermann was negative. An electrocardiogram taken during an attack (Fig. 7, a) shows slight inversion of the S-T segment in lead I and a deep depression of this portion of the curve in leads II and III, the S-T portion coming off below the iso-electric level. A record taken after the inhalation of amyl nitrite (with relief from symptoms) shows a deeper inversion of $\mathrm{T} 1$ but a less deep inversion of $\mathrm{T} 2$ and 3 . In addition the $\mathrm{S}-\mathrm{T}$ portion of the curve started at a higher level in lead II and near the iso-electric level in lead III. 
Case 8. A. C., female, aged 49. Diagnosis: Coronary sclerosis with angina pectoris. Pain in lower xiphoid region for two years with radiation to left shoulder and arm, related to effort and emotion. Blood pressure 142/82. Wassermann negative. An electrocardiogram taken as a control (Fig. 8, b) shows left axis deviation and T 1 and 2 are upright. T 3 is iso-electric. $1 \mathrm{cc}$. of 1-1000 solution of adrenalin hydrochloride was injected subcutaneously. This was followed by a typical attack of pain and a record taken 18 minutes after the injection (Fig. 8, a) shows a depression of the S-T segment in leads I and II with a low "take off." In lead III the S-T segment is curved with the convexity directed upwards and $\mathrm{T}$ is inverted.

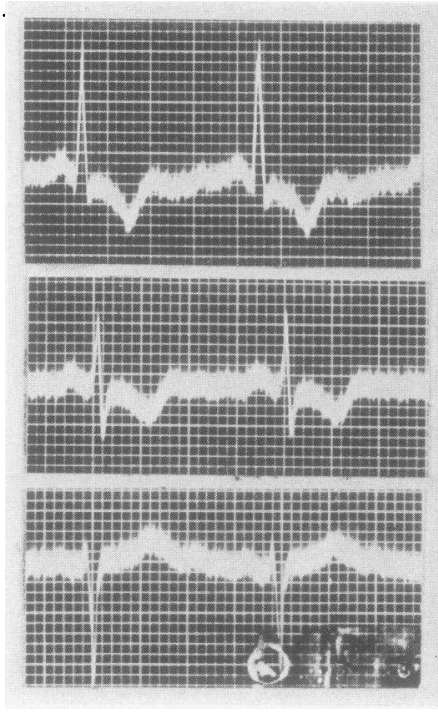

FIG. 6, a

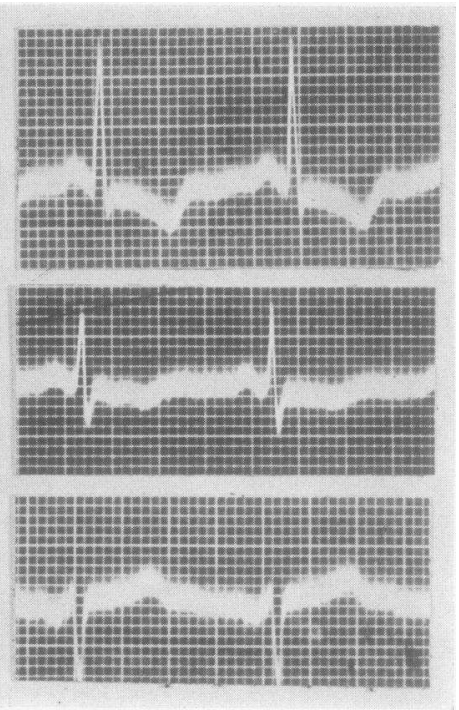

FIG. 6, b

Three patients with coronary sclerosis and angina of effort showed no significant electrocardiographic changes.

Case 9. F. R., female, aged 60, with typical substernal pain on effort. Coronary thrombosis one year previously. Blood pressure 156/84. Wassermann negative. Electrocardiograms during pain showed no change in the $\mathrm{T}$ wave.

Case 10. M. K., male, aged 58. Attacks of substernal pain of three years' duration caused by exertion. Blood pressure 164/90. Patient later developed coronary thrombosis and died. Electrocardiograms during attacks of angina showed no change.

Case 11. M. K., male, aged 43. Diagnosis: Coronary sclerosis with angina of effort. Sense of substernal oppression related to exertion and emo- 
tion. Radiation of pain to both arms. Duration one year. Blood Wassermann negative. Electrocardiogram taken after subcutaneous injection of $1 \mathrm{cc}$. of adrenalin hydrochloride 1-1000 solution showed very slight changes in the $\mathrm{T}$ wave. The patient suffered pectoral constriction.

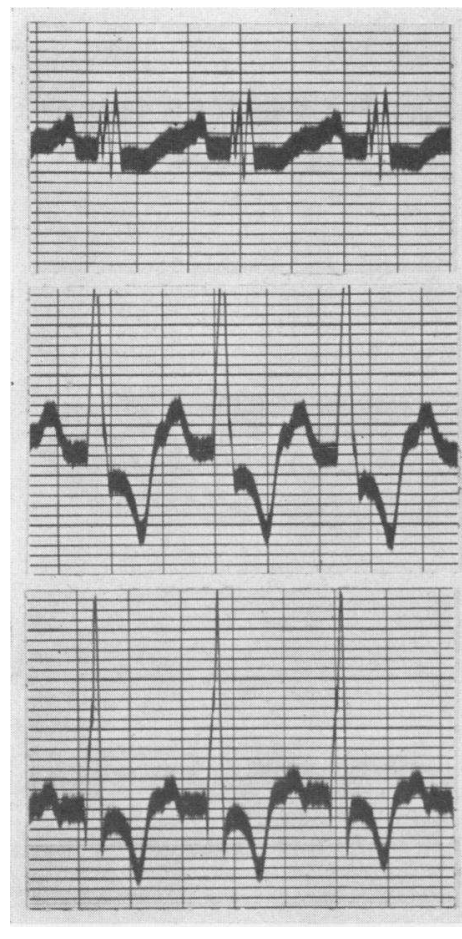

FIG. 7, a

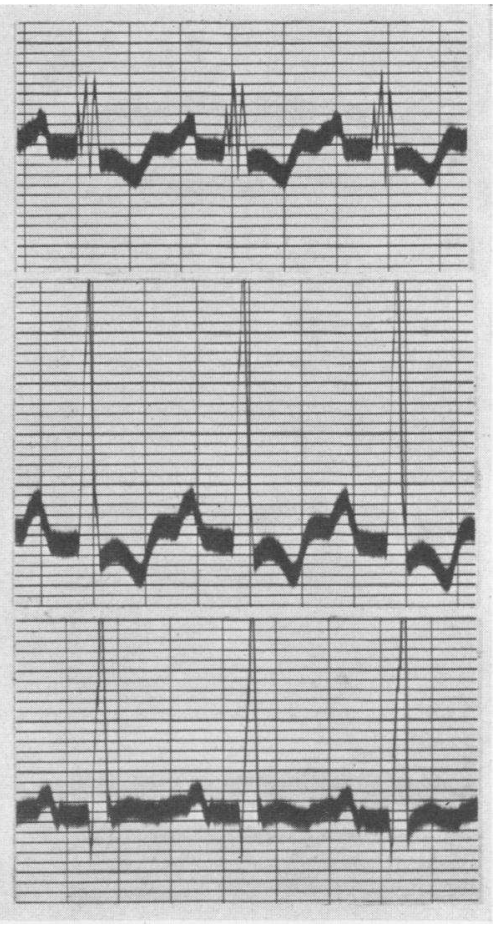

FIG. 7, b

\section{Electrocardiographic observations made during paroxysmal pain} not due to angina pectoris

1. Labor pains. Electrocardiograms were taken during active labor in five patients. In each case tracings of the standard leads were recorded during an interval when the uterus was relaxed. This was repeated while the patients were having severe uterine contractions which were visible and palpable. Records were again taken after the uterine contractions had subsided. In two cases records were obtained which showed some deviation from the normal which was present during both active contraction and during relaxation. In these two cases records were obtained a few days postpartum for comparison. 
In none of the five cases was any inversion of the $T$ wave or depression of the S-T segment of the curve observed during uterine contraction. In one case the T wave in lead III was depressed both during uterine contraction and relaxation. A record taken six days postpartum showed less inversion of $\mathrm{T} 3$.

2. Renal and biliary colic. One patient had severe biliary colic and was found at operation to have pericholecystitis with numerous adhesions. Records taken during biliary colic showed no deviation from the record taken after relief from pain.

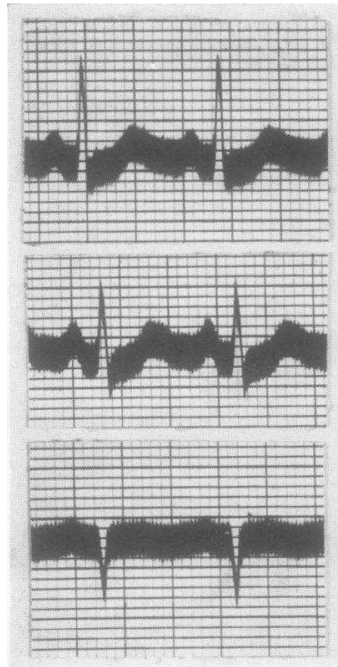

FIG. 8, a

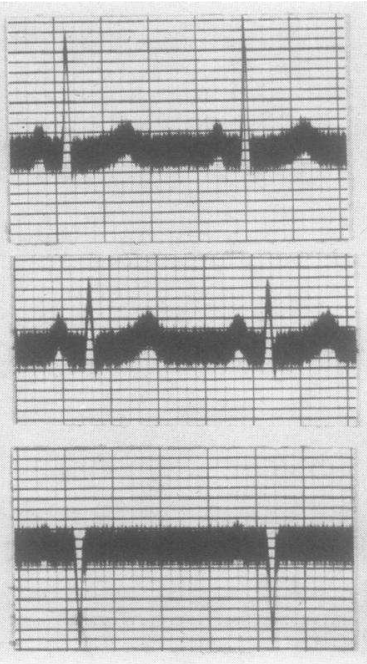

FIG. 8, b

Two cases of renal colic were investigated. One who had severe colic for several days had marked sinus arrhythmia which disappeared with relief from pain. However, neither of these two cases presented any alteration of the $\mathrm{S}-\mathrm{T}$ segment or $\mathrm{T}$ wave during pain.

\section{DISCUSSION}

The changes in the $\mathrm{T}$ wave and $\mathrm{S}-\mathrm{T}$ segment which occur frequently (in more than 50 per cent of cases) during attacks of angina pectoris are indicative of myocardial changes which are not related to exercise (Wolferth, personal observations) or to reflex effects from pain as such (labor pain, gallbladder and renal colic). In one patient, with a 
gastric ulcer and paroxysmal epigastric pain, slight depression of the $T$ wave occurred which varied in successive beats and was perhaps related to changes in the axis of the heart. In eight cases electrocardiographic changes were associated with characteristic pain (due to effort or emotion) and subsided with rest and inhalation of amyl nitrite. Myocardial changes may then be said to be associated with transient anginal attacks and this may be due to spasm of the coronary arteries or to transient variations in the coronary flow (reversal of coronary flow). The inversion of $\mathrm{T}$ or the $\mathrm{S}-\mathrm{T}$ segment in the electrocardiogram during brief paroxysms of pain of angina pectoris gives additional evidence of the nature of the anginal attack and may be helpful diagnostically.

\section{CONCLUSIONS}

Electrocardiographic observations are reported in eleven additional cases made during transient attacks of angina pectoris. In eight of these patients, there was inversion of the $T$ wave and (or) inversion of the $\mathrm{S}-\mathrm{T}$ segment of the curve. In some instances a negative $\mathrm{T}$ became more deeply depressed. These changes disappeared after subsidence of the pain. This evidence supports the conception that transient anginal attacks are due to myocardial ischemia, presumably due to alteration in coronary artery flow. Electrocardiograms taken during other types of paroxysmal pain (labor pains, renal and gallstone colic) did not show any changes in the $\mathrm{T}$ wave or $\mathrm{S}-\mathrm{T}$ portion of the curves.

\section{BIBLIOGRAPHY}

1. Arrilaga, M. F. C., Bull et mém. Soc. méd. d. hôp. de Paris, 1924, xlviii, 1493. Signification Pronostique De L'Électrocardiogramme Dans Les Insuffisances Cardiaques.

2. Bousfield, G., Lancet, 1918, ii, 457. Angina Pectoris: Changes in Electrocardiogram During Paroxysm.

3. Clerc, A., Presse méd., 1927, xxxv, 499. Anomalies Électrocardiographiques Au Cours De L'Oblitération Coronarienne.

4. Feil, H. and Siegel, M. L., Am. J. Med. Sci., 1928, clxxv, 255. Electrocardiographic Changes During Attacks of Angina Pectoris.

5. Levy, J. R., Arch. d. mal. du coeur, 1929, xxii, 523. Valeur Sémiologique Des Altérations Du Complexe Ventriculaire Électrique Dans Les Syndrome Angineux.

6. Parkinson, John and Bedford, D. Evan, Lancet, 1931, 15. Electrocardiographic Changes during Brief Attacks of Angina Pectoris. 
7. Wood, F. C. and Wolferth, C. C., Arch. Int. Med., 1931, xlvii, 339. Angina Pectoris: The Clinical and Electrocardiographic Phenomena of the Attack and their Comparison with the Effects of Experimental Temporary Coronary Occlusion.

8. Feil, H. S., Katz, L. N., Moore, R. A., and Scott, R. W., Am. Heart J., 1931, vi, 522. The Electrocardiographic Changes in Myocardial Ischemia.

9. Heberden, W., Med. Trans. Coll. Phys., 1768-70, ii, 58. Angina Pectoris. 